\title{
Heat of Dilution Calculation for 19 Molar Sodium hydroxide with Water for Use in 241-S-112
}

\author{
พ. B. Barton \\ CH2M Hill Hanford Group, Inc. \\ Richland, WA 99352 \\ U.S. Department of Energy Contract DE-AC27-99RL14047
EDT/ECN: UC:
Cost Center: $7 \times 400 \quad$ Charge Code: 502799
B\&R Code: $\quad$ Total Pages: 11 \\ Key Words: Caustic, Dilution, Sodium Hydroxide, Corrosion control, \\ 241-S-112, stress relieve carbon steel, Heat of Dilution
}

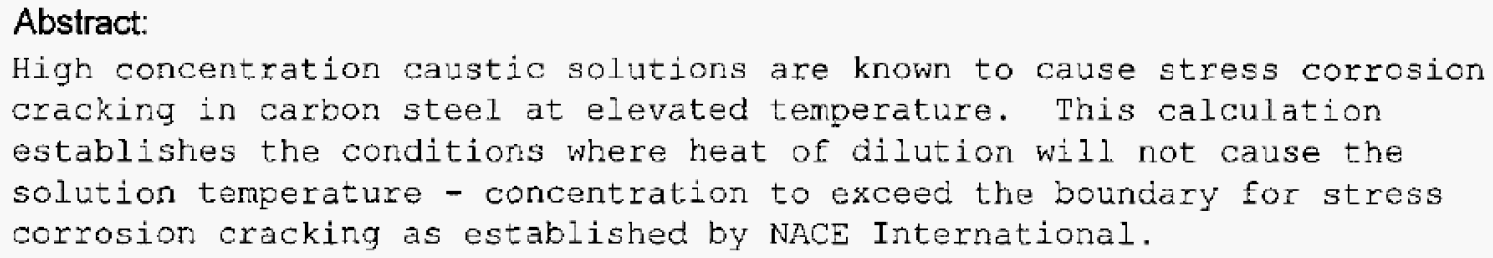

TRADEMARK DISCLAIMER. Reference herein to any specific commercial product, process, or service by trade name, trademark, manufacturer, or otherwise, does not necessarily constitute or imply its endorsement, recommendation, or favoring by the United States Government or any agency thereof or its contractors or subcontractors

Printed in the United States of America. To obtain copies of this document, contact: Document Control Services, P.O. Box 950, Mailstop H6-08, Richland WA 99352, Phone (509) 372-2420; Fax (509) 376-4989.

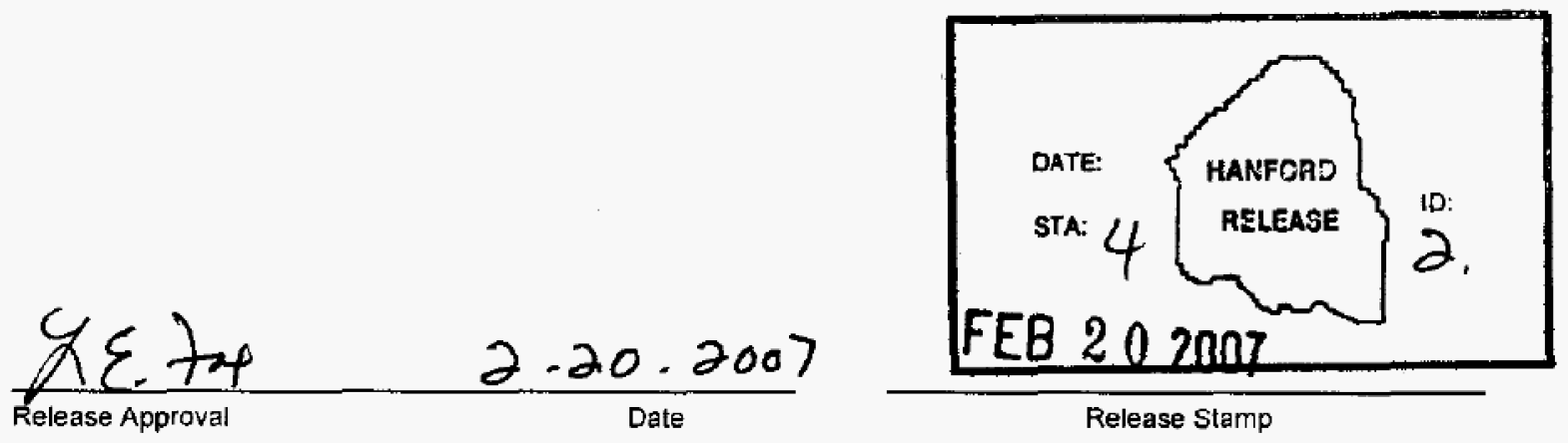

\section{Approved For Public Release}


Rev. 0

Calculation Reviewed: Heat of Dilution Calculation for 19 Molar Sodium Hydroxide with Water for Use in 241-S-112

Scope of Review: document and figures

Engineer/Analyst: W. B Barton WB. Barto. Date: $2 / 12 / 07$

Organizational Manager: M. J. Sutev

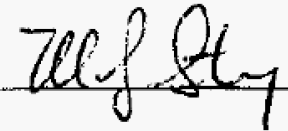

Date: $2 / 14 / 07$

This document consists of 9 pages and the following attachments (if applicable): none

Yes No NA*

[X] [ ] [ ] 1. Analytical and technical approaches and results are reasonable and appropriate.

[X ] [ ] [ ] 2. Necessary assumptions are reasonable, explicitly stated, and supported.

[] [ ] [X] 3. Ensure calculations that use software include a paper printout, microfiche, CD ROM, or other electronic file of the input data and identification to the computer codes and versions used, or provide alternate documentation to uniquely and clearly. identify the exact coding and execution process.

[X] [ ] [ ] 4. Input data were checked for consistency with original source information.

[X] [ ] [ ] 5. Key input data (e.g., dimensions, performance characteristics) that may affect equipment design is identified.

[ ] [ ] [X] 6. For both qualitative and quantitative data, uncertainties are recognized and discussed and the data is presented in a manner to minimize design interpretations.

[] [] [X] 7. Mathematical derivations were checked, including dimensional consistency of results.

[X] [ ] [ ] 8. Calculations are sufficiently detailed such that a technically qualified person can understand the analysis without requiring outside information.

[] [] [X] 9. Software verification and validation are addressed adequately.

[ ] [ ] [X] 10. Limits/criteria/guidelines applied to the analysis results are appropriate and referenced. Limits/criteria/guidelines were checked against references.

[X] [ ] [ ] 11. Conclusions are consistent with analytical results and applicable limits.

[X] [ ] [ ] 12. Results and conclusions address all points in the purpose.

[X] [ ] [ ] 13. Referenced documents are retrievable or otherwise available.

[X] [ ] [] 14. The version or revision of each reference is cited.

[X] [] [] 15. The document was prepared in accordance with Attachment A, "Calculation Format and Preparation Instructions." 


\section{RPP-CALC-32668 \\ Rev. 0}

Page 2 of 9

[] [] [X] 16. Impacts on requirements have been assessed and change documentation initiated to incorporate revisions to affected documents, as appropriate.

[X] [] [ ] 17. All checker comments have been dispositioned and the design media matches the calculations.

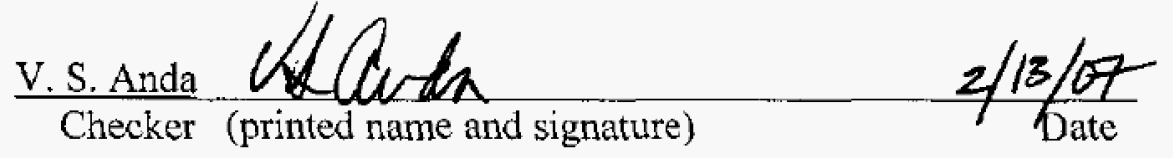

* If No or NA is chosen, an explanation must be provided on or attached to this form.

3. NA, Calculations don't use software.

6. NA, Uncertainty is not discussed. Data are presented in two ways which helps to reduce interpretation.

7. NA, No mathematical derivations are performed.

9. NA, Software is not used.

10. NA, Limits are not applied to analysis results (resuits are used to set limits).

16. NA, No impact on requirements exist, revisions have not been incorporated. 
Title: Heat of Dilution Calculation for 19 Molar Sodium Hydroxide with Water for Use in 241-S-112

Originator: W.B. Barton $W B B$ arton

Date: $2 / 12 / 07$

Date:

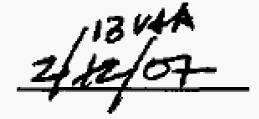

Organizational Manager: M. J. Sutey

Date:

\section{Purpose}

It is planned to put caustic ${ }^{1}$ solution into $S-112$ to use as a dense carrier fluid to help retrieve the solids from the tank. The caustic will also provide the needed corrosion inhibiting chemical in SY-102, the receiver tank for the transfer. This calculation will establish a safe envelope of concentration vs. temperature for the caustic in S-112 to ensure that stress corrosion cracking will not occur in the tank liner. NACE International has issued Standard Recommended Practice, RP0403-2003 Item No. 21102, Avoiding Caustic Stress Corrosion Cracking of Carbon Steel Refinery Equipment and Piping (NACE, 2003). This practice establishes recommended conditions to store caustic in non-stress relieved carbon steel piping and vessels and will be used as the bounding acceptable condition.

\section{Problem Statement}

Find the maximum caustic soda solution concentration ( 50 wt $\%$ or less) for which acceptable conditions of temperature and concentration can be defined to remain within the NACE criteria for a non-stress relieved carbon steel vessel assuming the caustic may be diluted with water while in the vessel.

\section{Input Data}

The site raw water temperature is currently $\sim 40^{\circ} \mathrm{F}$ and experiences an annual variation from 38 to $65^{\circ} \mathrm{F}$. This establishes a minimum temperature that water can be added to the caustic soda solution. A water heater is available that can heat the water to any desired temperature below $180^{\circ} \mathrm{F}$. The calculation will establish the maximum temperature for water.

Tank S-112 waste currently has a temperature of about $62^{\circ} \mathrm{F}$. (PCSACS).

Standard commercial concentrations of caustic soda are 25 and 50 weight $\%$ solutions. Other concentrations can be purchased at additional cost. 25 weight $\%$ caustic freezes at $-4{ }^{\circ} \mathrm{F}\left(-20^{\circ} \mathrm{C}\right)$ and 50 weight $\%$ caustic freezes at about $54{ }^{\circ} \mathrm{F}\left(12^{\circ} \mathrm{C}\right)$. These establish minimum temperatures for the caustic solution. In practice because of the high viscosity of caustic soda solution near freezing the practical minimum temperature is at least $10^{\circ} \mathrm{F}$. above these temperatures.

\footnotetext{
'Caustic and caustic soda are common names used for sodium hydroxide. In this document all three names will be used interchangeably.
} 
Title: Lleat of Dilution Calculation for 19 Molar Sodium Hydroxide with Water for Use in $241-\mathrm{S}-112$

Originator: W. B. Barton $\omega B B$
Checker: V.S. Anda WWh/

Date: $2 / 12 / 07$

Date: $2 / 13 / 67$

Organizational Manager: M. J. Sutey

Date:

\section{Method of Analysis}

The mixing of water and sodium hydroxide is known to be an exothermic reaction. Thus the calculation will have to look at all conditions of mixing between water and the maximum caustic concentration and compare it with the NACE recommendation.

The heat of dilution of caustic solutions has been studied and reported extensively in existing literature. Many commercial suppliers of caustic publish handbooks of the properties of caustic soda solutions. For this calculation the data and graphic calculations published in The Caustic Soda Solution Handbook, available on the Dow Chemical Company website is used (Dow, 2004). Similar handbooks are available from other suppliers.

On pages 16 and 17 of Dow, 2004, an Enthalpy-Concentration Chart for caustic soda solutions is provided. This chart can be easily used to determine the temperature of any dilution of a caustic solution with another caustic solution or water assuming the starting conditions of concentration and temperature for each stream are known. The calculation also assumes no loss of heat to the environment. The following instructions are given on page 17 of Dow, 2004.

"To determine the temperature of the final solution resulting from the dilution of a caustic soda solution, assuming no heat loss by radiation.

Problem: What is the temperature of the resultant $20 \%$ caustic solution obtained by using water at $80^{\circ} \mathrm{F}\left(27^{\circ} \mathrm{C}\right)$ to dilute $50 \%$ solution at $120^{\circ} \mathrm{F}\left(49^{\circ} \mathrm{C}\right)$ ?

Solution: From the intersection of the $120^{\circ} \mathrm{F}$ ( $49^{\circ} \mathrm{C}$ ) curve and the $50 \%$ caustic line, run a straight edge to the intersection of the $80^{\circ} \mathrm{F}\left(27^{\circ} \mathrm{C}\right)$ curve and the $0 \%$ line. The temperature of the $20 \%$ solution may be read at the point where the straight edge crosses the $20 \%$ line. It is found to be approximately $142{ }^{\circ} \mathrm{F}$ ( 62 $\left.{ }^{0} \mathrm{C}\right) . "$

The straight line connecting the initial conditions of the two streams defines the temperature curve experienced during adiabatic mixing to any dilution between the two streams. An expanded version of the graph from the Dow publication (figure 6 in Dow, 2004) including the area of interest is reproduced as Figure Ibelow.

\section{Assumptions}

As previously stated, the graphical calculation assumes adiabatic mixing of the two streams. This assumption of no heat loss to the environment is bounding because it 
Title: Heat of Dilution Calculation for 19 Molar Sodium Hydroxide with Water for Use in $241-\mathrm{S}-112$

Originator: W. B. Barton $48 B$

Date: $2 / 12 / 07$

Date: $2 / 3 / 67$

Organizational Manager: $\underline{\text { M. J. Sutey }}$

Date:

overestimates the temperature that will occur in actual non-adiabatic conditions where heat is lost to the environment.

The minimum temperature for water is assumed to be $65^{\circ} \mathrm{F}$ and the minimum temperature for the starting caustic solution is $64^{\circ} \mathrm{F}$. These are based on the input data.

The temperature envelope for the starting conditions must be at least $10^{\circ} \mathrm{F}$ wide to allow for field uncertainties.

The graphical solution published in Dow 2004 provides sufficient accuracy for the purpose of this calculation.

\section{Calculation}

Since the purpose of this calculation is to define a bounding case for caustic addition the NACE recommended temperature vs. concentration curve will be compared to the dilution curves developed using the enthalpy - concentration diagram from Dow. On Figure 1, the NACE curve is reproduced using $X$ marks to identify the points taken from the NACE chart. The line connecting the points marked $A$ and $B$ represents the adiabatic temperature from the mixing of the two species. Point A represents water at $80^{\circ} \mathrm{F}$. Point $\mathrm{B}$ is 50 weight $\%$ sodium hydroxide solution at $80^{\circ} \mathrm{F}$. These points were chosen as these conditions represent the maximum temperature - concentration conditions which maintain the solution conditions within the envelope for non-stress relieved carbon steel as defined by NACE.

Figure 2 is the NACE chart with the adiabatic temperature curve drawn in as read from Figure 1. Note that the temperature / concentration curve for dilution approaches but does not cross the boundary at which NACE recommends stress relief of welds and bends. 


\section{RPP-CALC-32668 \\ Rev. 0}

Page 6 of 9

Title: Heat of Dilution Calculation for 19 Molar Sodium Hydroxide with Water for Use in $241-\mathrm{S}-112$

Originator: $\mathrm{W} . \mathrm{B}$. Barton $\angle Q B$

Checker: V.S. Anda

(1) adx

Date: $2 / 12 / 07$

Date: $2 / 3 / 07$

Organizational Manager: $\underline{M}$. J. Sutey

Date:

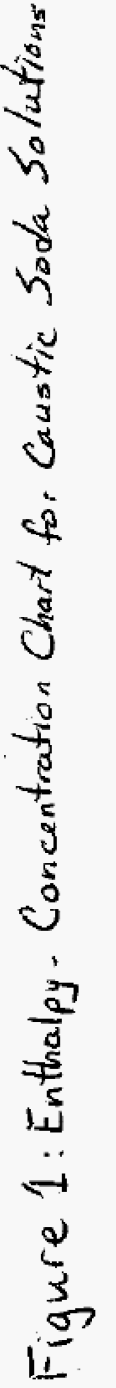

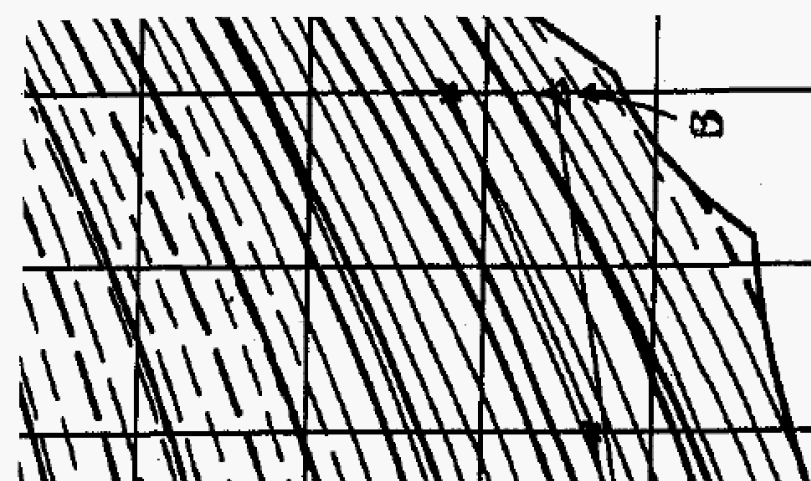

1 II I

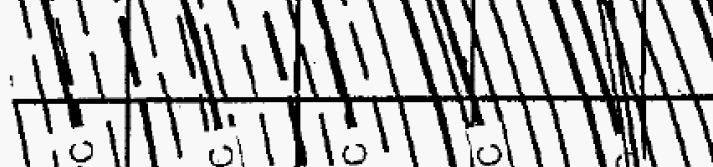

1017 of 110

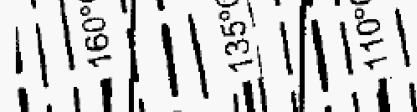

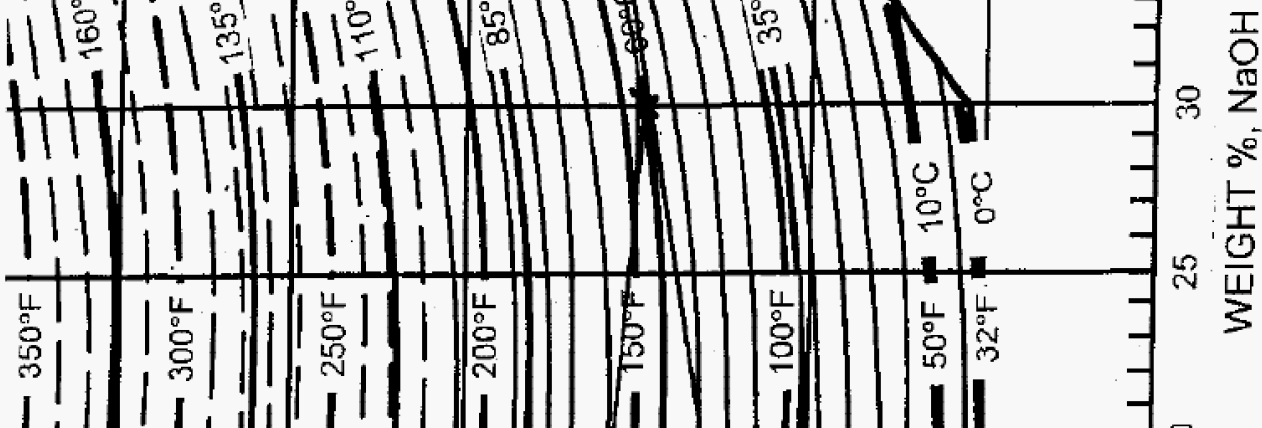

8

:
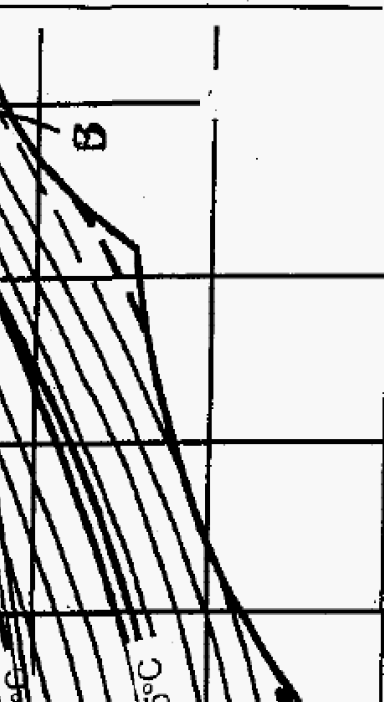

7 


$$
\begin{aligned}
& \text { RPP-CALC-32668 } \\
& \text { Rev. } 0
\end{aligned}
$$

Page 7 of 9

Title: Heat of Dilution Calculation for 19 Molar Sodium Hydroxide with Water for Use in 241-S-112

Originator: W. B. Barton $W B B$

Date: $2 / 12 / 07$

Checker: V.S.Anda l $140 \mathrm{ded}$

Date: $2 / 13 / 69$

Organizational Manager: M. J. Sutey

Date:

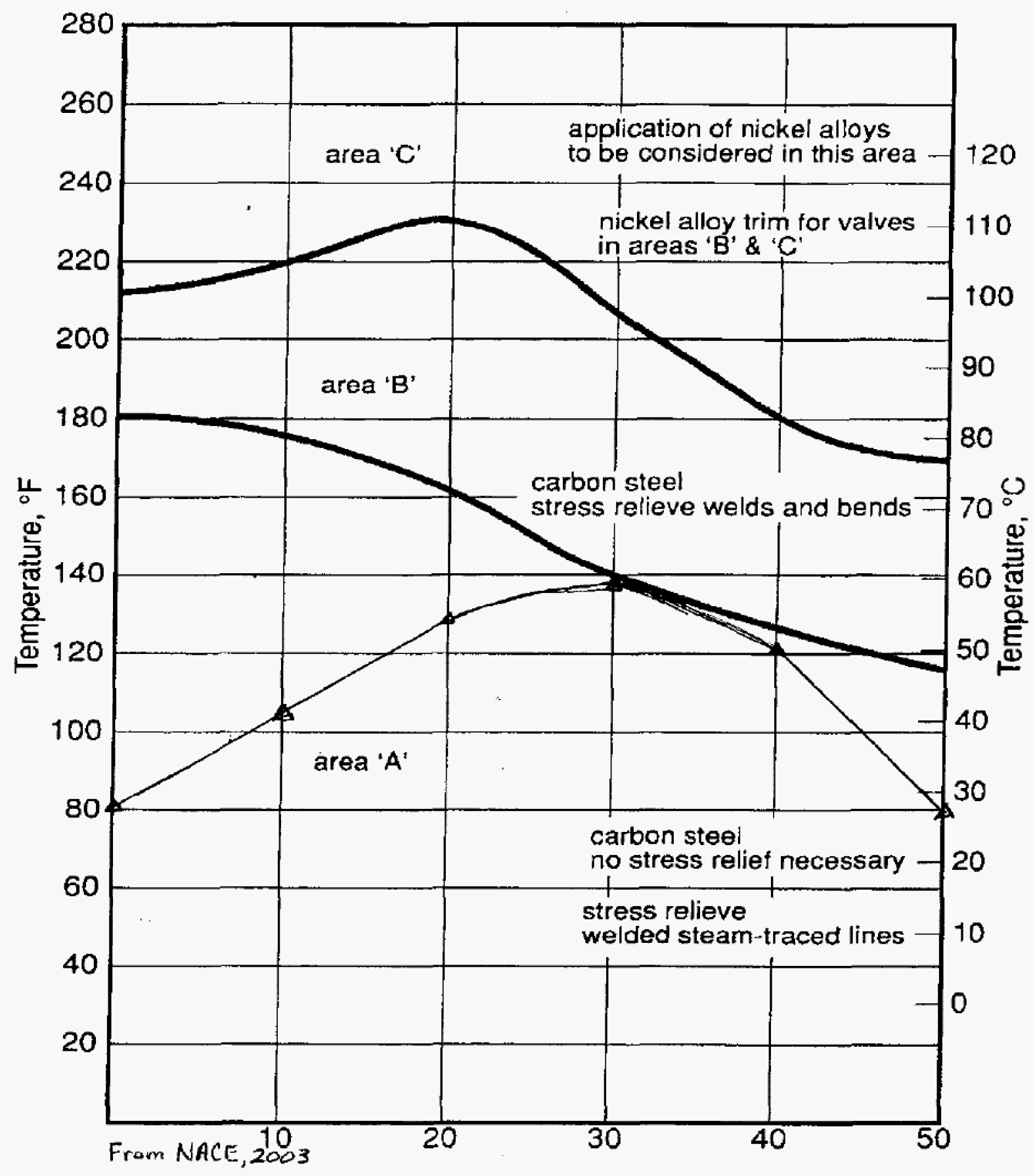

Concentration $\mathrm{NaOH}, \%$ by weight

Figure 2: Caustic Soda Service Chart 
Title: Heat of Dilution Calculation for 19 Molar Sodium Hydroxide with Water for Use in 241-S-112

$\begin{array}{ll}\text { Originator: W. B. Barton WBB } & \text { Date: } \frac{2 / 12 / 07}{\text { Checker: V.S. Anda VQ Qunde }} \text { Date: } 2 / 13 / 07\end{array}$

Organizational Manager: ‥ J. Sutey

Date:

\section{Results and Conclusions}

If the initial conditions of the caustic and water are at or below $80^{\circ} \mathrm{F}$ the mixing/dilution reaction of 50 weight \% caustic and water will not heat the solution to a temperature which exceeds the NACE recommendation for caustic storage in non-stress relieved carbon steel tanks. The following considerations support the conclusion that the above calculation is bounding.

- The calculation is done at $80^{\circ} \mathrm{F}$. The actual tank and waste temperature is below $65^{\circ} \mathrm{F}$. Thus the tank will act as a heat sink and absorb much of the heat released by the dilution reaction resulting in maximum temperatures less than those calculated.

- The first dilution that will be experienced will be the caustic solution coming in contact with the waste currently stored in S-112. There is less than 1000 gallons of water in tank S-112. This will initially react with $\sim 4,000$ gallons (one truck load) of 50 weight $\%$ (19 molar) caustic solution. This will then mix with two more truck loads of caustic ( $\sim 8,000$ gallons). Most of the remaining dilution will occur during the transfer to SY-102 where dilution water will be added at the pump to bring the concentration of the caustic as received at SY-102 down to approximately 25 weight $\%$ ( $\sim 8$ molar) caustic.

- Water will not be added as a continuous stream. Any water additions in S-112 will be in small increments. There will be plenty of time for the heat of reaction to be dispersed to the tank and its surrounding environment ensuring that maximum temperatures calculated will not be reached.

- The caustic will be ordered for delivery with a temperature of $70-80^{\circ} \mathrm{F}$. If the temperature of the received caustic exceeds $80^{\circ} \mathrm{F}$, it will be cooled before being introduced into the tank.

- Raw water is always significantly below $80^{\circ} \mathrm{F}$ as delivered to the $\mathrm{S}$ tank farm. There is a water heater that will be used to warm the water to $65-70^{\circ} \mathrm{F}$. The temperature is measured downstream of the heater and the water will be shutoff if the temperature exceeds $80^{\circ} \mathrm{F}$.

- The NACE chart of recommended conditions is designed for use of the equipment at the conditions. The caustic is planned to be in $S-112$ for less than 15 days, allowing only a short exposure time to initiate stress corrosion cracking. 


$$
\begin{aligned}
& \text { RPP-CALC-32668 } \\
& \text { Rev. } 0
\end{aligned}
$$$$
\text { Page } 9 \text { of } 9
$$

Title: Heat of Dilution Calculation for 19 Molar Sodium Hydroxide with Water for Use in $241-\mathrm{S}-112$

Originator: W. B. Barton WBB $\quad$ Date: $\frac{2 / 12 / 07}{2 / 13 / 07}$

Organizational Manager: M. J. Sutey

Date:

It is recommended that $50 \mathrm{wt} \%$ caustic at a temperature between 70 and $80^{\circ} \mathrm{F}$ be used for the caustic addition to tank S-112. Solutions at the upper end of this range will have better handling characteristics. Dilution water should be less than $80^{\circ} \mathrm{F}$.

\section{References}

Dow , 2004, The Caustic Soda Solution Handbook, Dow Chemical Company, Midland, Michigan, downloaded from .dow.com/causticsoda/lit/

NACE, 2003, Standard Recommended Practice - Avoiding Caustic Stress Corrosion Cracking of Carbon Steel Refinery Equipment and Piping, NACE Standard RP04032003, NACE International, Houston, Texas.

PCSACS, 2007, Surveillance Analysis Computer System, February 5, 2007 [Tank 241-S112 temperature], HISI ID No. 242, CH2M HILL Hanford Group, Inc., Richland, Washington. 